\title{
New Standards To Prevent Needle-stick Injury
}

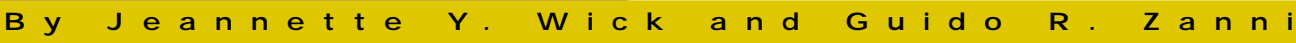

$\mathrm{R}$ ecent legislation revising the Occupational Safety and Health Administration's (OSH A's) regulations on preventing needle-stick injuries (NSI) became mandatory in April 2001 and impacts managed care providers and their members in interesting ways. The most immediate impact requires the consideration of the use of sharps that employ safety features; if alternatives to the use of sharps exist, these too should be employed.

Say "occupational hazard" and most people will envision hard hats, safety glass$\mathrm{es}$, and heavy industrial equipment. But carpal-tunnel syndrome and back strain have largely displaced mangled limbs as occupational hazards. Consequently, workplace hazards don't seem as dangerous. Workers routinely develop healthy respect for certain tools, and circumstances command appropriate precautions. For health care workers, the hypodermic syringe is one such tool.

Federal interventions address all types of sharps (any device that has a needle or sharp device attached to it). Syringes, however, are of most importance to managed care pharmacy. Certain questions arise regarding their use. Why are syringes and needles such a problem? In an era in which cost containment is an increasing challenge, what budget impact will new safety devices have? How will the switch to non-injectable alternatives affect the formulary or the multi-tiered payment

\section{Based on an estimat-} ed 800,000 NSI annu-

ally, total costs are conservatively put at about $\$ 480$ million.

structure? Will legislation, particularly at the state level, eventually extend to outpatient dispensing of syringes? Should these safety devices be covered for members who use injectable drugs at home now?

Unquestionably, syringes and needles save lives and are a staple in our arsenal of medical devices, but we have known for decades that injury with a contaminated needle can transmit disease. For years, our main concern was hepatitis. Today, more than 20 blood-borne pathogens have been transmitted via a needlestick-related injury. Three are of particular concern: hepatitis B virus, hepatitis C virus, and human immunodeficiency virus. Table 1, page 350, describes the perils associated with each of these.

In 1983, 17,000 workers acquired hepatitis B; today experts estimate that better work practices have reduced the number remarkably - to 800 annually. ${ }^{1}$ Better work practices, education, and personal protec- tive equipment have successfully reduced transmission of all blood-borne pathogens over the past decades. They have, however, reached the limits of their efficacy. Changes in equipment design are now necessary to further decrease NSI.

\section{Federal Mandates}

During the past decade, several agencies of the federal government have tried to heighten NSI awareness and have mandated prevention. Beginning this year, the use of safer sharps is no longer discretionary; legislation has been enacted mandating the following, effective April 17, 2001:

- Reduce sharps use if alternatives exist.

- Review and update exposure plans annually.

- Evaluate the effectiveness of safety devices.

- Solicit front-line worker participation in reviewing and selecting safety devices.

- In organizations employing 20 or more workers, maintain a sharps injury log documenting all NSI by worker occupation, device involved, and exposure circumstance. ${ }^{2}$

Supplementing federal law, 19 states have passed stricter NSI-prevention legislation; 10 more have bills pending. Some actually dictate the type of safety device to be considered. ${ }^{3}$ These regulatory standards have serious implications for managed care organizations and pharmacies,

\section{Authors}

JEAN NETTE Y. WICK, R.Ph., is Chief Pharmacist and Director of Quality Improvement and GUIDO R. ZAN NI, Ph.D., is Senior Health Systems Analyst in the District of Columbia's D epartment of M ental Health.

AUTHOR CORRESPON DENCE: Jeannette Y. Wick, R.Ph., Chief Pharmacist, Department of M ental Health, 306 7th St., NE, Washington, DC 20002; Tel: 202-645-9900; E-mail: JYWickRPh@aol.com.

Views expressed in this article represent those of the authors and not the District of Columbia Department of M ental Health.

Copyright $\odot 2001$ Academy of M anaged Care Pharmacy, Inc. All rights reserved. 
New Standards To Prevent Needle-stick Injury

\begin{tabular}{l|l|c|c}
\hline TA B LE 1 Blood-borne Pathogens of Significant Concern & \multicolumn{1}{c}{ Manifestations } & Transmission Rate & \multicolumn{1}{c}{ Treatment } \\
\hline Pathogen & $\begin{array}{l}\text { Can be asymptomatic, or manifest } \\
\text { itself with flu-like symptoms, } \\
\text { nausea, anorexia, dark urine, or } \\
\text { jaundice. It usually resolves spon- } \\
\text { taneously, but may be quite severe } \\
\text { in its presentation. }\end{array}$ & $6 \%-30 \%$ & $\begin{array}{l}\text { The most difficult cases can be treated } \\
\text { with interferon, a costly and disagree- } \\
\text { able agent. }\end{array}$ \\
\hline Hepatitis C (HCV) & $\begin{array}{l}\text { Asymptomatic in 75\% of cases, } \\
\text { but causes between 8,000 and } \\
10,000 \text { deaths from HCV-induced } \\
\text { liver disease annually. }\end{array}$ & about 1.8\% & Prevention is the only intervention. \\
\hline $\begin{array}{l}\text { Human immunodeficiency virus } \\
\text { (HIV) }\end{array}$ & $\begin{array}{l}\text { Steadily progressive depletion of } \\
\text { the immune system followed by } \\
\text { opportunistic infection, wasting, } \\
\text { and death. }\end{array}$ & $0.3 \%$ & $\begin{array}{l}\text { A variety of antiviral drugs and sup- } \\
\text { portive measures, costing more than } \\
\$ 12,000 \text { annually. }\end{array}$
\end{tabular}

Source: Wick J. The other silent epidemic: Prevention and control of hepatitis C. Consultant Pharmacist 1999; 14(7): $721-32$.

particularly those that are national in scope. Failure to meet these standards will result in swift and sometimes severe financial penalties.

\section{Occupational Hazards}

Every day, 2,100 of our nation's eight million health care workers experience a needle-stick.1, ${ }^{4}$ Experts have estimated total needle-sticks at between 600,000 and 800,000 incidents annually.1, 4, 5 Of these, half (mainly outside the hospital setting) are unreported. ${ }^{1,5}$

Nurses experience the greatest number of NSI. They account for $49.7 \%$ of reported cases, followed by physicians at $12.6 \% .^{5}$ Laboratory personnel, housekeepers, and pharmacists also are at significant risk. ${ }^{1}$

Most incidents occur in patient rooms $(37 \%)$, operating rooms $(16 \%)$, and emergency departments (7\%). ${ }^{5}$ The overall rate for NSI in hospitals is $27 \mathrm{NSI}$ per 100 beds per year. ${ }^{5}$

Using a standard sharp device, NSI are predictable:

- Approximately $38 \%$ of NSI occur during needle use; $42 \%$ occur after use. ${ }^{1}$

- Risk of NSI increases when devices must be taken apart or manipulated. ${ }^{1}$

- Needles that are attached to tubing or are difficult to use increase risk. ${ }^{1}$

Five primary activities are associated with NSI: needle disposal, injection administration, blood draw, needle-cap replacement, and trash or dirty-linen removal. ${ }^{5}$

\section{Anatomy of a Needle}

To the naked eye, a syringe looks like a simple device: It consists of a barrel, a plunger, and a needle. But these and all sharps must be engineered precisely to ensure that they are sterile, accurate, easy to use, and as painless as possible. In the past 50 years, manufacturing advances have created reliable disposable products that are remarkably inexpensive; traditional syringes cost three to four cents each.

According to the Centers for Disease Control (CDC), approximately $62 \%-88 \%$ of NSI can be prevented by replacing traditional sharps with safer medical devices. ${ }^{4}$ In 1999, the CDC's National Institute for Occupational Safety and Health (NIOSH) issued "Preventing N eedle-stick Injuries in Health Care Settings." ${ }^{11}$ This alert is userfriendly, and points to the importance of using improved engineering controls in the context of a comprehensive NSI-prevention program. The guidelines stress careful evaluation of all new devices, with extensive worker involvement in all aspects of the assessment. Accessibility of the device selected and acceptability of any product to the employees who will use it are the cornerstone of any program's design. The reason is clear: Health care workers in different practice locations will have different needs. NIOSH's program guidelines are summarized in Figure 1, page 351.

Newer devices have been developed to bolster safety. The Food and Drug Administration (FDA) suggests five features to protect health care workers, described in Figure 2, page 352. Sharps and syringes are currently described in four ways: (1) Traditional devices offer no protection; (2) Active devices require some action by the health care worker to engage protection-improper use eliminates any protection; (3) Accessory safety devices depend on employee compliance, and although they provide protection, are not considered ideal; and (4) Passive safety devices are ready to use, and protect the user before, during, and after the injection is administered.

Passive devices, because they cannot be circumvented, are preferred by most legislators and employees. They do not hinder patient care and, at the same time, protect workers. ${ }^{1,5}$ 


\section{Achieving Compliance with OSHA Reporting Requirements}

The Exposure Prevention Information Network (EPINet) at the International Health Care Worker Safety Center in Charlottesville, Virginia, provides assistance and standardized methods for recording $\mathrm{NSI}$ and blood and body fluid contacts, consistent with OSHA requirements. EPINet uses a uniform injuryreport format that allows easy data entry and analysis. To date, more than 1,500 hospitals use EPIN et. Advantages of using EPINet include the analysis of NSI by occupation, device, and procedure. EPINet also evaluates new devices. Participating facilities share data and preventive measures. For additional information about EPIN et, call 804-982-0702.

\section{Pharmacy's Role}

Pharmacists, whose main exposure to $\mathrm{NSI}$ has been in the sterile intravenous hood, often develop a sense of distance from this threat. But their risk of infection is increasing. Managed care pharmacists work in three roles impacted by NSI legislation: as personal work practice, as purchasing decision maker, and as clinical health care provider.

With ample sterile needles at their disposal and few exposures to contaminated sharps, pharmacists who work in the sterile hood may be less vigilant than other heal th care employees. Consequently, attention to good practices wanes, and NSI occur. Sharps disposal units should be easy to use and replaced frequently. Poor hood technique may result in improper needle disposal, putting others at risk for downstream exposure. For example, when a needle is accidentally thrown in the paper trash, housekeepers and trash-removal personnel are at risk. With no information about the needle, contamination must be assumed. The organization will incur costs of prophylactic treatment and monitoring.

Many pharmacists perceive no risk from clean NSI and do not report them. Reporting NSI, even those resulting from clean needles, helps track the type of device most likely to be involved, or work practices that contribute to $\mathrm{NSI} .^{3}$

Pharmacists responsibilities are expanding into immunization and administration of chemotherapeutics, radiopharmaceuticals, and other injectables. Managed care has promoted these activities, as they are cost-effective and convenient. For clinicians, use of every available protection is imperative. They must be involved in assessment of proposed safety devices.

\section{Patient Protections}

In traditional dispensing, safety devices offer certain advantages. Home use of injectable drugs and fluids is increasingly common; pharmacists must help plans decide whether safety devices are a necessity or luxury. People with acquired immunodeficiency syndrome (AIDS), diabetes, cancer, infertility problems, and a host of other conditions inject drugs at home. Doing so avoids hospitalization and saves health care dollars. Although many drugs are self-administered by the patient, some are administered by family members. In the latter situation, safety devices may prevent the spread of infection. In both circumstances, safety devices may protect others from downstream risk. Pharmacists will need to be familiar with various types of sharps, and also with their operation.

As purchasers, pharmacists must be informed of NSI prevention efforts so that products ordered, maintained, and dispensed by the pharmacy meet requirements. In this role, pharmacists represent employers and must implement prevention mandates. The involvement of pharmacists with NSI tracking and analysis minimizes risk. Pharmacists should review local and national NSI data and contribute information from their own facilities. Although EPINet does not track pharmacy-specific NSI, participation in EPIN et is advantageous. ${ }^{6}$

\section{Implications for Managed Care Plans and Pharmacists}

The effectiveness of medical devices with safety features has been clearly established. In addition to NSI reduction fig-

\section{FIG URE 1) NIOSH's Program Guidelines \\ - Organizations must analyze needle-stick and sharps-related injuries to identify hazards and trends. \\ - Employers must set priorities and plan strategies relying on local and national information about risk factors and successful interventions.}

- Employers must promote and monitor the adequacy of employee training.

- Work practices contributing to needlestick injuries must be modified.

- Employers must promote safety awareness.

\section{- Employers should establish blameless reporting systems, and conduct follow-up on all needle and sharps-related injuries.}
- Employer evaluation of prevention efforts should be followed by performance feedback to all employees.

Source: U.S. Department of Health and Human Services, Centers for Disease Control and Prevention, $\mathrm{N}$ ational Institute for $\mathrm{O}$ ccupational Safety and Health. NIOSH Alert: Preventing N eedle-stick Injuries in Health Care Settings. DHHS Publication N 0. 2000-108, 1999.

ures of $62 \%-88 \%$ cited earlier, phlebotomy injuries were reduced by $76 \%$ with self-blunting needles, and by $82 \%$ with the use of a needle shield. One hospital achieved almost a 90\% reduction in NSI with the combined use of safety devices and worker training. ${ }^{\text {? }}$

A decision to switch to safety syringes is not budget neutral; recall that a traditional syringe costs about four cents. Safety devices can cost up to 25 cents per device, or approximately $\$ 70,000$ per year for the average 300-bed hospital. But consider the alternative. Each uncomplicated NSI costs between $\$ 500$ and $\$ 600$ for laboratory charges, treatment, and follow-up. ${ }^{8}$ Actual costs are probably higher if lost work time and decreased productivity are considered. Subsequent liability litigation may increase costs. Based on an annual estimate of $800,000 \mathrm{NSI}$, total annual costs 


\begin{tabular}{ll}
\hline FIG URE 2 & FDA Recommendations \\
& for Safety Features
\end{tabular}

- Safety devices should provide a barrier between hands and needle after use.

- The safety feature should allow or require the worker's hands to remain behind the needle at all times.

- The feature should be part of, not an accessory to, the device; this is called an integrated device.

- The feature should work before, during, and after use (to protect downstream workers). This is preferable; it is called a passive safety system.

- The feature should be simple and easy to use, requiring little or no training.

Source: U.S. Department of Health and Human Services, Centers for D isease Control and Prevention, $\mathrm{N}$ ational Institute for Occupational Safety and Health. NIOSH Alert: Preventing N eedle-stick Injuries in Health Care Settings. DHHS Publication N 0. 2000-108, 1999.

for NSI are conservatively estimated to be $\$ 480$ million. Data confirm that safety devices prevent injuries; the use of safety devices is a wise business decision and a good preventive measure. Increased facility operating costs get passed on to managed care organizations through per member per month patient costs and upward pressure on premiums.

$\mathrm{N}$ ew federal mandates clearly advocate a multi-faceted approach to preventing $\mathrm{NSI}$, the first step being the use of alternatives where they exist. This has formulary implications if al ternative drug-delivery systems are available. In the near future, for example, insulin will be available in an inhaler, which will likely cost more than the injectable form. Additional concerns are raised if alternatives are available but at the second or third tier of a multi-tiered payment plan. Clearly, each organization will have to analyze costs and risks carefully.

\section{The Future}

Ultimately, experimental technologies are expected to reduce the use of sharps over the next few years. Several needle-free injection devices are already in use, and currently there are more than a dozen FDA-approved needle-free injectors. ${ }^{9}$ They are not currently standardized, and can be extremely costly. Some patients experience local reactions, pain, or delayed soreness on a level that is equal to or slightly worse than from a needle. ${ }^{9}$ Advances will improve the utility and cost of needle-free devices.

When multiple or routine samples are needed, alternatives to sharps are a research priority. The newest glucose-testing devices do not require blood. Some drug levels, for example lithium, can be measured in saliva, thus reducing the need for blood samples. For the time being, cost is a barrier to implementation of many of these new techniques.

\section{Conclusion}

Science may someday eliminate sharps entirely. History may call them crude and invasive tools. Until then, they remain essential tools of our trade, and emphasis on safe handling is imperative. Transmission of blood-borne pathogens in health care settings is rare, but facts on the low probability of contracting a life-threatening disease from NSI are only comforting when they apply to someone else.

\section{References}

1. U.S. Department of Health and Human Services, Centers for Disease Control and Prevention, National Institute for Occupational Safety and Health. NIOSH Alert: Preventing N eedle-stick Injuries in Health Care Settings. DHHS Publication No. 2000-108, 1999.

2. International Health Care Worker Safety Center. Effective date for OSHA's revised bloodborne pathogens standard. April 12, 2001. See www.med.virginia.edu/medcntr/centers/epinet/ effdate.html. Accessed April 2001.

3. International Health Care Worker Safety Center. Exposure Prevention Information N etwork. See www.med.virginia.edu/medcntr/centers/epinet/ Accessed July 2001.

4. U.S. Department of Labor, Occupational Safety and Health Administration. Needle-stick prevention. Available at www.osha-slc.gov/needlestick/index.html. Accessed April 2001.

5. U.S. Department of Labor, Occupational Safety and Health Administration. Safer needle devices: Protecting health care workers. Available at www.osha-slc.gov/SLTC/needle-stick/ saferneedledevices/saferneedledevices. $h$ tml. Accessed April 2001.

6. E-mail correspondence with Ginger B. Parker, International Health Care Worker Safety Center, Charlottesville, VA, May 1, 2001.

7. Rosenstock L. Testimony by the Director of National Institute for Occupational Safety and Health, Center for Disease Control and Prevention, before the Subcommittee on Workforce Protections, Committee on Education and the Workforce, U.S. House of Representatives, June 22, 2000. Available at www.cdc.gov/ niosh/ndletest.html.

8. Jagger J, Bentley M, Juillet E. Direct cost of follow-up for percutaneous and mucocutaneous exposures to at-risk body fluids: Data from two hospitals. Advances in Exposure Prevention 1998; 3: 3 .

9. Bykowski M. Needle-free injections face obstacles. Pediatric News 1999; 33(5): 16. 